\title{
Effect of annealing temperature on amorphous indium zinc oxide thin films prepared by a sol-gel spin-coating method
}

\author{
Sang-Hyun Lee, Seung-Yup Lee and Byung-Ok Park ${ }^{\dagger}$ \\ Department of Inorganic Materials Engineering, Kyungpook National University, Daegu 702-701, Korea
}

(Received October 21, 2011)

(Revised November 22, 2011)

(Accepted December 2, 2011)

\begin{abstract}
Transparent conductive indium zinc oxide thin films were prepared by spin-coating a sol-gel solution. Zinc acetate dihydrate $\left[\mathrm{Zn}\left(\mathrm{CH}_{3} \mathrm{COO}\right)_{2} \cdot 2 \mathrm{H}_{2} \mathrm{O}\right]$ and indium acetate $\left[\mathrm{In}\left(\mathrm{CH}_{3} \mathrm{COO}\right)_{3}\right]$ were used as starting precursors, and 2methoxyethanol with 1-propanol as solvents. Upon annealing in a temperature range from 500 to $1000^{\circ} \mathrm{C}$, the thin film crystallizes into polycrystalline $\operatorname{In}_{2} \mathrm{O}_{3}(\mathrm{ZnO})$. The lowest electrical resistivity was obtained at an annealing temperature of $700^{\circ} \mathrm{C}$ as $2 \Omega \cdot \mathrm{cm}$. Average optical transmittances were higher than $80 \%$ at all annealing temperatures. These experimental results confirm that the sol-gel spin-coating can be a good simplified practical method for forming transparent electrodes.
\end{abstract}

Key words Sol-gel, Indium-zinc oxide, Electrical properties and measurements, Optical properties

\section{Introduction}

Transparent conducting oxide (TCO) thin films have received extensive attention because of their diverse applications as transparent electrodes for optoelectronic devices such as flat panel displays and solar cells. Among the TCO films, ITO is well known as the most commonly used materials because of low resistance and high optical transparency. However, Superior characteristics to improve the electrical conductivity of ITO films were chosen instead of the IZO. Recently, indium-zinc oxide [1-7] and numerous studies have shown. In particular, Moriga et al. [1] revealed nine homologous compounds of $\mathrm{In}_{2} \mathrm{O}_{3}(\mathrm{ZnO})_{\mathrm{k}}$ composition $(\mathrm{k}=3,4,5,6,7,9$, 11,13 and 15).

Usually, IZO thin films were prepared by a pulsed laser deposition (PLD) [3-5] or magnetron sputtering method $[6,7]$. In these ways, highly c-axis oriented and well crystallized thin films were obtained. However, it was difficult to obtain such well crystallized thin films from sol-gel spin-coating method $[8,9]$. We revealed in our former paper [10-13] that the crystallized IZO films showing a strong orientation along c-axis can be achieved by extremely decreasing the solution concentration. However, the crystallized thin films prepared by sol-gel spincoating have not possessed better properties than amor-

\footnotetext{
Corresponding author

Tel: +82-53-950-5634

Fax: +82-53-950-5645

E-mail: bopark@knu.ac.kr
}

phous films, rather worse properties. Thus, not crystalline films but amorphous films needed to be investigated. In this work, we studied the effects of annealing temperature on the IZO films whose crystal structure was amorphous.

\section{Experimental}

Indium solution and zinc solution were separately prepared in order to prepare a clear starting solution for IZO film, and then the two solutions were mixed. First, the indium solution was prepared. Indium acetate $\left(\mathrm{In}\left(\mathrm{CH}_{3} \mathrm{COO}\right)_{3}\right)$ was dissolved in 1-propanol by stirring the solution at $85^{\circ} \mathrm{C}$ for 1 hour. Diethanolamine (DEA) was added as a stabilizer. The molar ratio of DEA/In was 1.5. Second, zinc acetate dihydrate $\left(\mathrm{Zn}\left(\mathrm{CH}_{3} \mathrm{COO}\right)_{2}\right.$. $2 \mathrm{H}_{2} \mathrm{O}$ ) was used as precursor material for the zinc solution. The zinc acetate dehydrate and monoethanolamine (MEA) were dissolved in 2-methoxyethanol, and the solution was stirred at $50^{\circ} \mathrm{C}$ for $40 \mathrm{~min}$. The molar ratio of MEA (stabilizer) to $\mathrm{Zn}$ was the unity. Third, the indium and zinc solutions were mixed and stirred at room temperature for $2 \mathrm{hrs}$ and finally, the starting solution $(0.06 \mathrm{M})$ for the thin films was completed.

The starting solution for IZO film was dropped onto quarts glass substrate $(15 \times 15 \times 1 \mathrm{~mm})$ and rotated at $3000 \mathrm{rpm}$ for $30 \mathrm{sec}$. The substrate was cleaned in an ultrasonic bath with acetone, ion exchanged water, and ethanol successively. After each coating process by spin- 
Table 1

The results of Hall measurement IZO thin films with postannealing treatment

\begin{tabular}{llll}
\hline Post-annealing conditions & $\rho(\mathrm{cm})$ & $\mathrm{n}\left(\mathrm{cm}^{-3}\right)$ & $\mu\left(\mathrm{cm}^{2} / \mathrm{Vs}\right)$ \\
\hline No post-annealing & 0.14 & $5.65 \times 10^{18}$ & 7.95 \\
Inert atmosphere $\left(\mathrm{N}_{2}\right)$ & 0.05 & $1.12 \times 10^{19}$ & 10.6 \\
Reducing atmosphere $\left(\mathrm{N}_{2}+6 \% \mathrm{H}_{2}\right)$ & 0.02 & $3.26 \times 10^{19}$ & 9.87 \\
\hline
\end{tabular}

ning, the coated layer was pre-annealed at $400^{\circ} \mathrm{C}$ for $10 \mathrm{~min}$ on a hot plate. The process from coating to preannealing was repeated for the desired thickness (approximately $250 \mathrm{~nm}$ ). The films were then annealed in an electric furnace.

The structural property of the films was analyzed using $\mathrm{X}$-ray diffractometer (XRD) with $\mathrm{CuK} \alpha$ radiation operated at $40 \mathrm{kV}, 30 \mathrm{~mA}$. The microstructure of the films was examined by scanning electron microscopy (SEM) at $20 \mathrm{kV}$. The electrical properties such as the resistivity, the carrier concentration, and the Hall mobility were determined by measure by using a four-probe van-der-Paw technique. Optical transmittance was measure by an ultraviolet visible near-infrared spectrophotometer.

\section{Results and Discussion}

Figure 1 shows the XRD patterns of the IZO thin films at various annealing temperatures. An amorphous phase with a broad diffraction peak at $2 \theta=30 \sim 37^{\circ}$ was observed from 400 to $700^{\circ} \mathrm{C}$. As the temperature increased, the main peak of indium oxide appeared at $2 \theta=30.6^{\circ}$. Moreover, the broad peak $\left(2 \theta=30 \sim 37^{\circ}\right)$ became

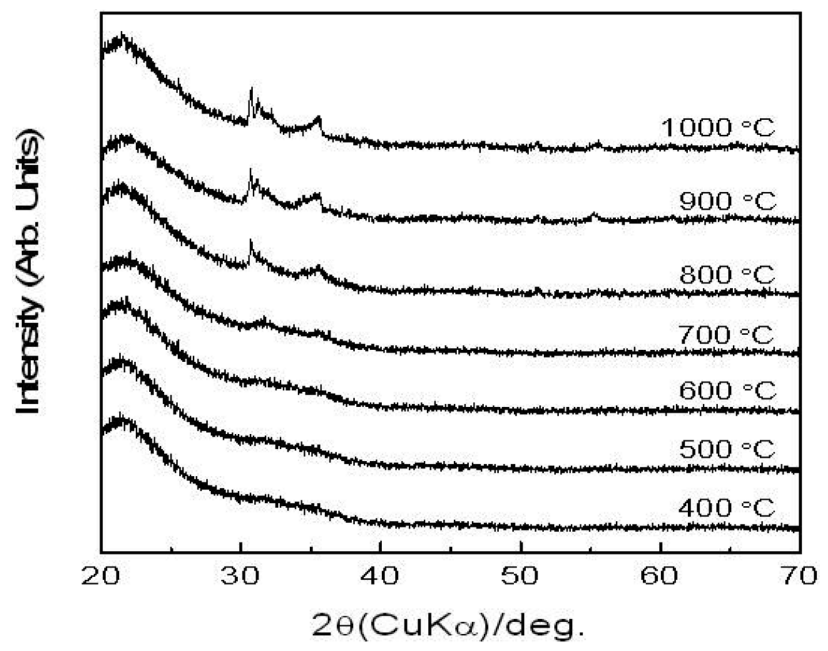

Fig. 1. The XRD patterns of indium zinc oxide films with annealing temperature.
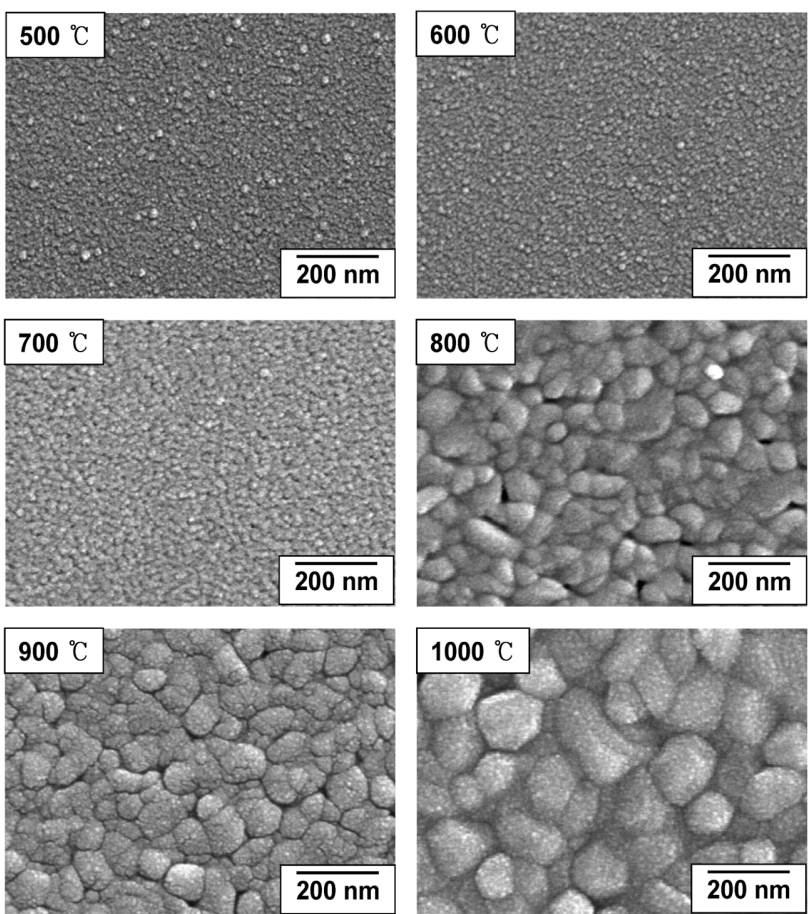

Fig. 2. The surface morphologies of the thin films with annealing temperature.

rather higher with temperature. This might be because the IZO simultaneously including diverse compositions werea on the way to crystallize [3]. In fact, most of the strong peaks from diverse compositions of indium zinc oxides were located between 30 and $37^{\circ}$ [1]. Considering the frequency of the strong peaks found in the range, it was quite plausible that the broad peak was shaped like a wedge.

The microstructure of the thin films was shown in Fig. 2. There was a distinct difference in grain size between $500 \sim 700^{\circ} \mathrm{C}$ and $800 \sim 1000^{\circ} \mathrm{C}$. The grain size was $10 \sim 20 \mathrm{~nm}$ in the range of 500 to $700^{\circ} \mathrm{C}$ without conspicuous increase. As the temperature increased, the grain size suddenly increased to $90 \sim 130 \mathrm{~nm}$ at $800^{\circ} \mathrm{C}$ and then $150 \sim 270 \mathrm{~nm}$ at $1000^{\circ} \mathrm{C}$.

Figure 3 shows the dependence of electrical properties on the annealing temperature. At all temperatures, there was not significant change in mobility. The increment of the grain size in the range of over $800^{\circ} \mathrm{C}$ did not contribute to the increase of mobility. Maybe, this was because diverse compositions of the phases were blocking free electrons. The carrier concentration increased sharply and has the maximum value at $700^{\circ} \mathrm{C}$, and then started to decrease. Free carriers of IZO originate from donor sites associated with oxygen vacancies [14], so that the curve of the carrier concentration could be explained by oxygen vacancies. Adsorbed oxygen atoms 


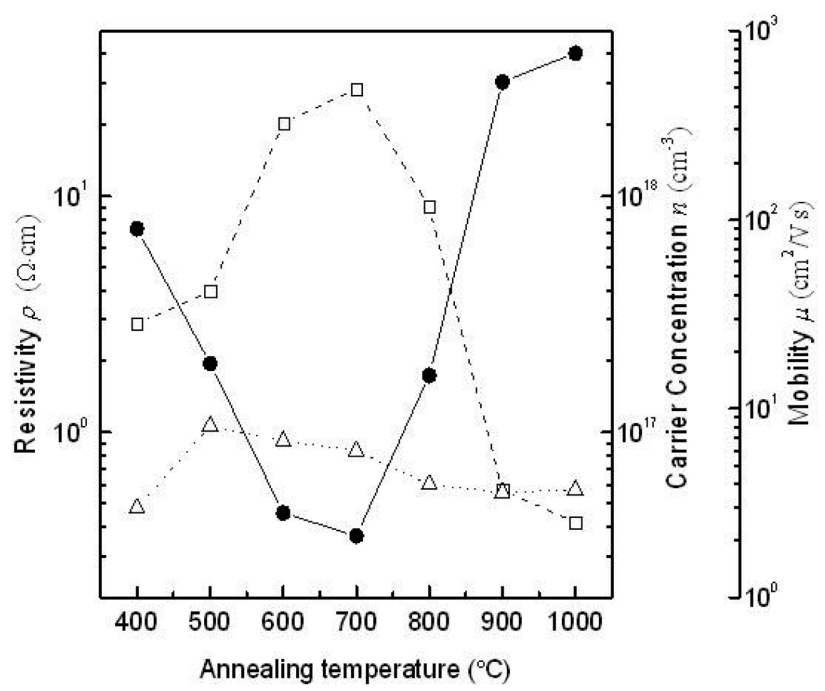

Fig. 3. Dependence of electrical properties on the annealing temperature: resistivity $\mathbf{O}$, carrier concentration $\square$, and mobility $\triangle$.

during pre-annealing desorbed in the annealing temperature up to $700^{\circ} \mathrm{C}$. As the temperature increases, the amount of oxygen desorption increased, and free carriers in the thin films also increased. However, the situation was reversed over $700^{\circ} \mathrm{C}$ because of oxygen diffusion into the thin films. At the temperatures, it was suspected that the oxygen vacancies in the films significantly decreased due to the oxygen compensation by the oxygen vacancies. As the temperature increase, the diffusion rate increased and the oxygen compensation also increased. The resistivity could be profiled from the carrier concentration and the mobility. We obtained a thin film of the lowest resistivity at $700^{\circ} \mathrm{C}$.

Figure 4 shows the optical transmittance of the IZO

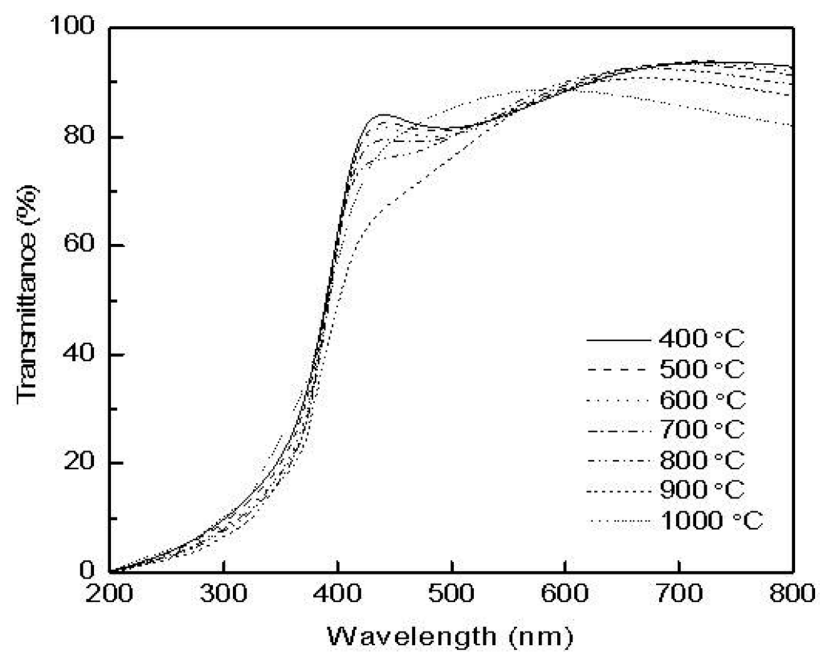

Fig. 4. The optical transmittance of the films deposited on quarts glass with the annealing temperature.

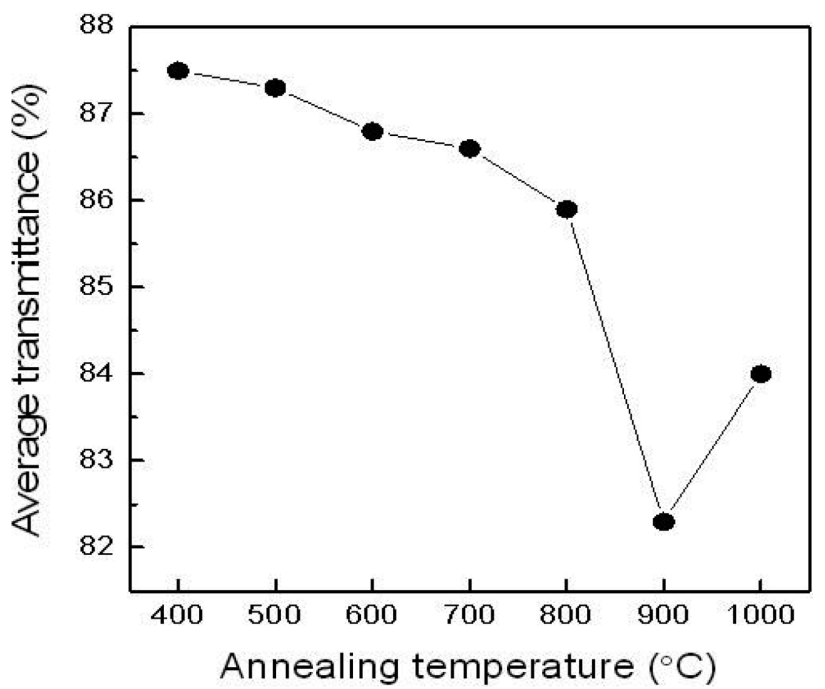

Fig. 5. Average transmittance in the visible region $(400 \sim 800 \mathrm{~nm})$ with the annealing temperature.

thin films coated on quarts glass substrate and annealed at $400 \sim 1000^{\circ} \mathrm{C}$. The transmittance falls sharply due to the onset of fundamental absorption. As the temperature increased, the absorption edge shifted towards long wavelengths. However, this was not in full accordance with the 'Moss-Burstein effect' [15] which said the optical band-gap is shifted towards short wavelengths with high carrier concentration values. In this work, although the carrier concentration increased between 400 with $700^{\circ} \mathrm{C}$, the absorption edge shifted towards long wavelengths. This might be due to the 'quantum confinement effect' [16] caused considerably by grain size of films. In fact, the grain size of the thin films was comparatively small in that range of temperature. At the temperature of $1000^{\circ} \mathrm{C}$, the transmittance profile was unusual and the average transmittance increased. It was suspected that a structural change begun at $1000^{\circ} \mathrm{C}$. Figure 5 shows the average transmittance profiles in the visible region $(400 \sim 800 \mathrm{~nm})$ with the annealing temperature. Overall visible region, average transmittances were over $80 \%$ at all annealing temperatures.

\section{Conclusion}

Transparent conductive indium zinc oxide thin films were prepared by spin-coating a sol-gel solution. The most of the strong peaks from diverse compositions of indium zinc oxides were located between $30^{\circ}$ and $37^{\circ}$. As the temperature increased, the grain size suddenly increased to $90 \sim 130 \mathrm{~nm}$ at $800^{\circ} \mathrm{C}$ and then $150 \sim 270 \mathrm{~nm}$ at $1000^{\circ} \mathrm{C}$. The lowest electrical resistivity was obtained 
at an annealing temperature of $700^{\circ} \mathrm{C}$ as $2 \Omega \cdot \mathrm{cm}$. All annealing temperatures yielded average optical transmittances higher than $80 \%$.

\section{References}

[ 1 ] T. Moriga, D.D. Edwards and T.O. Mason, "Phase relationships and physical properties of homologous compounds in the zinc oxide-indium oxide system", J. Am. Ceram. Soc. 81(5) (1998) 1310.

[2 ] K.Y. Son, D.H. Park, J.H. Lee, J.J. Kim and J.S. Lee, "Phase development procedure of $\operatorname{In}_{2} \mathrm{O}_{3}(\mathrm{ZnO})_{3}$ ceramics and its sintering behavior", Solid State Ion. 172 (2004) 425.

[ 3 ] L. Dupont, C. Maugy, N. Naghavi, C. Guery and J.M. Tarascon, "Structures and textures of transparent conducting pulsed laser deposited $\mathrm{In}_{2} \mathrm{O}_{3}-\mathrm{ZnO}$ thin films revealed by transmission electron microscopy", J. Solid State Chem. 158 (2001) 119.

[4] T. Moriga, M. Mikawa, Y. Sakakibara, Y. Misaki, K.I. Murai, I. Nakabayashi, K. Tominaga and J.B. Metson, "Effects of introduction of argon on structural and transparent conducting properties of $\mathrm{ZnO}-\mathrm{In}_{2} \mathrm{O}_{3}$ thin films prepared by pulsed laser deposition", Thin Solid Films 486 (2005) 53.

[ 5 ] N. Naghavi, C. Marcel, L. Dupont, A. Rougier, J.B. Leriche and C. Guery, "Structural and physical characterization of transparent conducting pulsed laser deposited $\mathrm{In}_{2} \mathrm{O}_{3}-\mathrm{ZnO}$ thin films", J. Mater. Chem. 10 (2000) 2315.

[6] G. Goncalves, P. Barquinha, L. Raniero, R. Martins and E. Fortunato, "Crystallization of amorphous indium zinc oxide thin films produced by radio-frequency magnetron sputtering", Thin Solid Films 516 (2008) 1374.

[7] Y.R. Park, E.K. Kim, D.G. Jung, T.S. Park and Y.S. Kim, "Growth of transparent conducting nano-structured $\mathrm{In}$ doped $\mathrm{ZnO}$ thin films by pulsed DC magne- tron sputtering", Applied Surface Science 254 (2008) 2250.

[ 8 ] K.J. Chen, F.Y. Hung, S.J. Chang and Z.S. Hu, "Microstructures, optical and electrical properties of In-doped $\mathrm{ZnO}$ thin films prepared by sol-gel method", Applied Surface Science 255 (2009) 6308.

[9] S.Y. Lee and B.O. Park, "Electrical and optical properties of $\mathrm{In}_{2} \mathrm{O}_{3}-\mathrm{ZnO}$ thin films prepared by sol-gel method", Thin Solid Films 484 (2005) 184.

[10] J.H. Lee, S.Y. Lee and B.O. Park, "Fabrication and characteristics of transparent conducting $\operatorname{In}_{2} \mathrm{O}_{3}-\mathrm{ZnO}$ thin films by ultrasonic spray pyrolysis", Mater. Sci. Eng. B 127 (2006) 267.

[11] Z.Q. Xu, H. Deng, Y. Li, Q.H. Guo and Y.R. Li, "Characteristics of Al-doped c-axis orientation $\mathrm{ZnO}$ thin films prepared by the sol-gel method", Mater. Res. Bull. 41 (2006) 354.

[12] G.S. Wang, D. Rémiens and C. Soyer, "Combined annealing temperature and thickness effects on properties of $\mathrm{PbZr}_{0.53} \mathrm{Ti}_{0.47} \mathrm{O}_{3}$ films on $\mathrm{LaNiO}_{3} / \mathrm{Si}$ substrate by sol-gel process", J. Cryst. Growth 293 (2006) 370.

[13] G. Machado, D.N. Guerra, D. Leinen, J.R. Ramos-Barrado, R.E. Marotti and E.A. Dalchiele, "Indium doped zinc oxide thin films obtained by electrodeposition", Thin Solid Films 490 (2005) 124.

[14] N. Naghavi, L. Dupont, C. Marcel, C. Maugy, B. Laïk, A. Rougier, C. Guéry and J.M. Tarascon, "Systemic study and performance optimization of transparent conducting indium-zinc oxide thin films", Electrochim. Acta 46 (2001) 2007.

[15] R. Ghosh, G.K. Paul and D. Basak, "Effect of thermal annealing treatment on structural, electrical and optical properties of transparent sol-gel $\mathrm{ZnO}$ thin films", Mater. Res. Bul. 40 (2005) 1905

[16] P.K. Ghosh, S. Jana, S. Nandy and K.K. Chattopadhyay, "Size-dependent optical and dielectric properties of nanocrystalline $\mathrm{ZnS}$ thin films synthesized via rf-magnetron sputtering technique", Mater. Res. Bul. 42 (2006) 505. 